\title{
Conformity to Traditional Gender Norms in a Feminized Occupation: The Influence on Health Behaviors
}

\author{
María del Pilar Sánchez-López ${ }^{1,2}$, Ana Isabel Saavedra' ${ }^{1,3}$, Virginia Dresch ${ }^{1,4}$, \\ Rosa Limiñana ${ }^{1,5}$ \\ ${ }^{1}$ Grupo de Investigación Estilos Psicológicos, Género y Salud, Universidad Complutense de Madrid, Madrid, \\ Spain \\ ${ }^{2}$ Departamento de Personalidad, Evaluación y Tratamientos Psicológicos II, Universidad Complutense de \\ Madrid, Madrid, Spain \\ ${ }^{3}$ Hospital Universitario de Getafe, Madrid, Spain \\ ${ }^{4}$ Departamento de Psicologia, Universidade Federal Fluminense, Rio de Janeiro, Brazil \\ ${ }^{5}$ Departamento de Personalidad, Evaluación y Tratamiento Psicológicos, Universidad de Murcia, Murcia, Spain \\ Email: virginiadresch@vm.uff.br
}

Received 17 September 2014; revised 2 November 2014; accepted 19 November 2014

Copyright (C) 2014 by authors and Scientific Research Publishing Inc.

This work is licensed under the Creative Commons Attribution International License (CC BY).

http://creativecommons.org/licenses/by/4.0/

(c) (i) Open Access

\begin{abstract}
The object of this study is to examine the relationships between conformity to traditional gender norms and health in a special group of the Spanish population, male/female nurses. Nursing is a particularly good example of feminized occupation. Spanish male $(n=98)$ and female $(n=98)$ nurses matched in diverse sociodemographic variables complete measures of gender norms and health behavior variables. Measures of conformity to gender norms in female and male nurses are compared with those of the general population. The analysis of the inter-gender relationships and health highlights a clearly masculine pattern for men and a clearly feminine one for women. A detailed analysis of the scores in each of the scales reveals a pattern of illness in male nurses that is still masculine despite their lower conformity, as a group, to masculine norms, and a clearly feminine illness pattern in female nurses. The consideration of gender from a multidimensional perspective (the different factors that make up Masculinity and Femininity, as assessed in this work) has allowed us to study the relations between gender norms and health in more detail. Limitations and implications are discussed.
\end{abstract}

\section{Keywords}

Health, Gender, Nursing, Spain 


\section{Introduction}

The purpose of the present study is a verification of the relationships between gender and health [1] in a special group of the Spanish population, male and female hospital nurses. We hypothesize that the coexistence of men and women in a professionally feminized setting such as nursing enables us to highlight the mechanisms of the relation between gender and health. Firstly, we shall examine whether this contributes to modifying the classic standards of masculine and feminine gender norms, the extent to which it determines a differential health profile in male and female nurses, as well as whether this health profile differs significantly from the traditionally masculine and feminine health patterns.

The consideration of gender as a marker to explain possible differences and inequalities within the health setting implies taking into account the biological factors tied to the sexed condition, such as factors explained by gender. Both have a profound impact on determining the health status. In fact, being a man or a woman may establish the differential propensity to certain health or illness statuses, different risk factors, or different treatment needs. Similarly, gender also exerts a powerful effect on health status: it may limit different rates of exposure to certain risks, different patterns in the quest for treatment, or differential impact of social and economic determinants of health.

An essential problem identified in works applying the gender approach is that comparative analysis of gender differences stops short and accepts the description of the differences between men and women as an explanation in itself [2]. The present work challenges these traditional tenets, considering gender from a broader perspective, as a tool that can reveal the impact of the social and work settings in which such health differences occur. Neglecting the biological factors associated with being a man or a woman from gender factors when examining their relationship with health may lead to masking the influence of gender on health.

Hence, our second starting point is based on the need to bear gender in mind and somehow to operationalize it. Gender is defined as the result of a process of evolution by which expectations and norms are internalized. Since the 1970s, empirical works on the meaning of femininity and masculinity began to take on importance [3]-[5] as socially constructed concepts that evolved historically. These early approaches were not very suitable because they used global indices and did not take into account the multidimensional nature that was revealed in the latest research works on the topic. On the basis of these critiques, authors like Mahalik [6] [7] introduced the concept of "social norm" as a basis for constructing tools for gender evaluation, based on the creation of an instrument measuring coherence with the traditional masculine and feminine role in groups of male and female students from the USA. Social norms are rules and standards understood and shared by the members of a group and they guide people's social behavior just as strongly as laws do. Thus, femininity and masculinity are a heterogeneous set of social norms about attitudes, beliefs and relationships that seem reasonable for men and women in a given culture. In order to analyze the relations between gender and health in female and male nurses, in this work, we adopted the concept of social gender norm of Mahalik [8]. Masculinity and femininity are therefore understood as the degree of conformity to a heterogeneous set of social norms about behaviors, attitudes, and beliefs that are appropriate for men and women [6] [7].

\subsection{Relationship between Gender and Health}

Our second starting point is the findings of the ever-increasing number of research papers that refer to a relationship between gender (operationalized as Masculinity/Femininity, M/F) and health. For example, some authors have shown that traditional masculinity is associated with drug abuse behavior in a study of students from the USA [6]-[9], several health behaviors in North American men [10], better mental health in Spanish men and women [11], less frequent use of mental health service when analyzing different studies in various nationalities [12], or greater self-esteem and lower levels of anxiety and depression in Hindu couples [13].

Likewise, other studies focusing on femininity and masculinity $(\mathrm{M} / \mathrm{F})$ find differing health styles related to M/F in Spanish women [14]. Some studies [15] [16], in Austrian and Spanish men and women, respectively, find that being a man or a woman and gender roles both influence health levels.

As confirmed in previous studies, men of all ages and nationalities are more prone to alcohol and tobacco consumption [17]. However, gender norms linked to the pursuit of status, relationships (playboy), dominance, and violence (see Table 1) show a more direct relationship with alcohol consumption: the higher the level of pursuit of status, dominance, promiscuity, and violence, the greater will be alcohol consumption, as confirmed in some studies carried out with North American and Spanish population [6] [18]. 
Table 1. Definitions and sample items for each of the subscales of the conformity to masculine norms inventory and conformity to feminine norms inventory.

\begin{tabular}{|c|c|c|}
\hline Scale & Definition of norm & Sample item \\
\hline CMNI & Masculine norm & Item \\
\hline Winning & Drive to win & In general, I will do anything to win \\
\hline Playboy & $\begin{array}{l}\text { Desire for multiple/noncommitted sexual } \\
\text { relationships } \\
\text { Emotional distance from sex partners }\end{array}$ & If I could, I would frequently change sexual partners \\
\hline Violence & Proclivity for physical confrontations & I believe that violence is never justified (reversed) \\
\hline Self-reliance & Aversion to asking for assistance & I ask for help when I need it (reversed) \\
\hline Risk-taking & Penchant for high-risk behaviors & In general, I do not like risky situations (reversed) \\
\hline $\begin{array}{l}\text { Power over } \\
\text { women }\end{array}$ & $\begin{array}{l}\text { Perceived control over women at both personal and } \\
\text { social levels }\end{array}$ & $\begin{array}{l}\text { I feel best about my relationships with women when } \\
\text { we are equals (reversed) }\end{array}$ \\
\hline Dominance & General desire to have personal control over situations & In general, I must get my way \\
\hline $\begin{array}{l}\text { Primacy of } \\
\text { work }\end{array}$ & Viewing work as a major focus of life & My work is the most important part of my life \\
\hline $\begin{array}{l}\text { Pursuit of } \\
\text { status }\end{array}$ & Being pleased with being thought of as important & It feels good to be important \\
\hline $\begin{array}{l}\text { Disdain for } \\
\text { homosexuals }\end{array}$ & $\begin{array}{l}\text { Aversion to the prospect of being gay, or being thought } \\
\text { of as gay }\end{array}$ & I would be furious if someone thought I was gay \\
\hline CFNI & Feminine norm & Item \\
\hline $\begin{array}{l}\text { Nice in } \\
\text { relationships }\end{array}$ & $\begin{array}{l}\text { Developing friendly and supportive relationship with } \\
\text { others }\end{array}$ & It is important to let people know they are special \\
\hline Thinness & Pursuing a thin body ideal & I am always trying to lose weight \\
\hline Modesty & $\begin{array}{l}\text { Refraining from calling attention to one's talents or } \\
\text { abilities }\end{array}$ & I always downplay my achievements \\
\hline Domestic & Maintaining the home & I enjoy spending time making my living space look nice \\
\hline $\begin{array}{l}\text { Care for } \\
\text { children }\end{array}$ & Take care and be with children & I would baby-sit for fun \\
\hline $\begin{array}{l}\text { Romantic } \\
\text { relationship }\end{array}$ & Investing self in romantic relationship & $\begin{array}{l}\text { Whether I'm in one or not, romantic relationships are often } \\
\text { on my mind }\end{array}$ \\
\hline $\begin{array}{l}\text { Sexual } \\
\text { fidelity }\end{array}$ & $\begin{array}{l}\text { Keeping sexual intimacy contained within one } \\
\text { committed relationship }\end{array}$ & $\begin{array}{l}\text { I would only have sex if I was in a committed } \\
\text { relationship like marriage }\end{array}$ \\
\hline $\begin{array}{l}\text { Invest in } \\
\text { appearance }\end{array}$ & $\begin{array}{l}\text { Committing resources to maintaining and improving } \\
\text { physical appearance }\end{array}$ & I’d feel superficial if I wore make-up (reversed) \\
\hline
\end{tabular}

From Parent and Moradi [61] and Mahalik et al. [7].

Similarly, for women, we found other studies in which the results show that they have poorer physical health and higher rates of chronic disease and disability than men, as in the study of Kirchengast and Haslinger [15] with Austrian population or that of Sánchez-López et al. [11] with Spanish rural population. In this case, according to studies carried out with Spanish [14] and Rumanian population [19], it seems that women with worse mental health express greater conformity to gender norms related to child care, romantic relations, drive for thinness, and the importance of attachments. However, at least in Spanish population, traditional femininity is a protector against substance consumption[18].

The influence of age on the relationship between $\mathrm{M} / \mathrm{F}$ and health has also been well documented [20], worldwide and in Australian population [21], stressing the fact that age and gender are associated with health-related behaviors.

\subsection{The Special Case of Hospital Nurses}

The group of male and female hospital nurses is particularly appropriate for our aims for two reasons. First, be- 
cause caring is thought to be "naturally" feminine and expected from a profession consisting of looking after people. It is largely a job undertaken by women, and this indeed does occur on a global scale, in countries as different as Spain, the United Kingdom, China, or Saint Kitts Island [22]-[25].

The case of male nurses is used as a paradigmatic example of the possible effect of sexual segregation on occupations in which one of the sexes predominates [26]-[28]. In the USA, male nurses, just because they are men, had a series of advantages that granted them accumulative benefits, thereby transforming the effect of being a minority into a positive factor. In contrast, these studies described the pressures of women in male-dominated occupations, as a result of their heightened visibility, social isolation, and negative role stereotyping. Furthermore, token men in female-dominated occupations experience few if any of these negative consequences; contrariwise, they are usually promoted to better posts sooner than the women (Williams, 1995). The question that arises is whether the professional setting leads to assuming a special gender regimen, embedded in a specific social environment, in the sense expressed by Connell and Messerschmidt [29], producing a pattern of masculinity that still predominates the feminizing practices of this profession.

The consulted studies of professional nursing measure gender role as a function of instrumentality and/or expressiveness, using the Bem Sex Role Inventory-BSRI [3]. An example is the study carried out with male Irish nurses, according to which they felt more identified with the feminine role than with the masculine one [30]. Likewise, the analysis carried out by Fisher [31] in an Australian comparative study found that male nurses were more androgynous, female nurses were more feminine, and male engineers were more masculine.

The second reason why this collective is especially interesting is the complex relation of health with the gender factors discussed in this specific setting, where two different groups coexist that can show the mechanisms relating $\mathrm{M} / \mathrm{F}$ to health: in one case, the women in an occupation in which they are the majority; in the other case, the men, who are a minority.

In fact, we may find very heterogeneous results on health. In a Canadian study of professional nursing staff, the men obtained higher scores in health than the women [32], and in the North American study carried out by Tucker, Harris, Pipe, and Stevens [33] with professionals of both sexes, the men generally reported good health, but more than one half of the sample was overweight, had backaches, and did not exercise on a regular basis. In female Japanese nurses, Ushiro and Nakayama [34] confirmed higher scores on women's traditional gender role than the general female Japanese population, also reporting that the nurses who scored higher in the traditional feminine gender role were more vulnerable to exhaustion at work and they provided worse care in their posts.

Particularly outstanding is the study by Talley, Thomas, and Brown [35], which compares male and female nurses from the USA with the general population of the USA, the UK, and Canada. Significant differences with the known normative populations were found only in the female sample of nurses from the 35 - 44 year age range. These female nurses had the lowest scores on both physical and psychological health and an increase in the Body Mass Index (BMI). The authors pointed out caring for small children, the spouse's unwillingness to share responsibilities, and not enough time to look after their own physical and mental health as significant risk factors for these ages.

A British study [36] compared two professions, one eminently feminine such as nursing and an eminently masculine profession, accountancy; aside from the differences between men and women, the results suggested that when men and women hold minority posts, there may be specific adverse gender effects for their health.

A recent study of the relations between gender and health in the field of Spanish professional nursing [16] highlights that higher alcohol consumption is related to more conformity to violence, a playboy attitude, and pursuit of status (see Table 1), a relationship that has already been proven in other social contexts [6] [14]. For male nurses, the study also found that higher conformity to some gender norms (emotional control, violence, dominance, disdain for homosexuals, and pursuit of status, see Table 1) imply better self-perceived health, fewer ailments, fewer visits to the doctor, and less medicine consumption. The study points out minor conformity to masculine norms for male nurses, although this does not seem to affect their health-related behaviors, which match the traditionally masculine health pattern. However, the data on female nurses are inconclusive[30], and, based on the relationships mentioned in the above-mentioned bibliography, to determine how this affects health would be another significant contribution of this work.

Basically, the studies carried out in different countries show a similar tendency: female nurses are more traditionally feminine, and male nurses are less traditionally masculine than the general population. This work will attempt to confirm whether this also occurs with male and female nurses in Spain. In addition, the studies in different countries also show that men in general and male nurses in particular report better health than women (in 
general) and female nurses (in particular). With this work, we will attempt to verify whether this also occurs in Spain. Lastly, studies in various countries examining the relations between different gender norms and health show a complex pattern, although always tending to confirm that the scales measuring traditional norms-such as Emotional control in the case of men and Romantic relationships or Investment in appearance in the case of women - reveal a clear relationship (positive or negative) with various health indexes. As no studies were found investigating these specific relations between male and female nurses, the present study will attempt to determine whether these relations also occur in Spanish nurses.

\subsection{The Present Study}

In order to better understand the differences in health in the case of male and female nurses and the contribution of the gender factors involved, our work is based on two essential issues that emerged in the reviewed bibliography and are discussed in the introduction: on the one hand, confirmation of the relations between gender and health and the need to investigate from a broader and more comprehensive gender approach; on the other hand, the study of the special case of male nurses and the impact of gender norms on health-related behaviors of male and female nurses, seeking new evidence of the complex processes of gender socialization in professional feminized settings and the relationship of such processes with health.

On the basis of the above-mentioned aims, we propose the following hypotheses:

Hypothesis 1: If sociodemographic and employment variables are equal, compared with the general population, male nurses will conform less to male norms, and female nurses will conform more to female norms.

A British study [37] with female athletes (that acts as a mirror case to that presented in this study) indicates that professional practice or choice may contribute to the design of a profile expressing higher or lower conformity to gender norms, depending on whether the profession or activity is considered to be socially more masculine or feminine.

In fact, studies with different instruments, for example, the BSRI [31] [34] and the Conformity to Male Norms Inventory-CMNI/Conformity to Female Norms Inventory-CFNI [6] [7] [16], obtain similar results, in which female nurses score high in femininity and male nurses low in masculinity.

Hypothesis 2: Differences between male and female nurses in aspects relating to health will highlight the existence of a differential health pattern for men, which is unlike the pattern for women.

Recent studies [16] [38] verified that health differences in male and female nurses seem to be related to the specific setting where this profession is practiced.

Hypothesis 3: Despite lower conformity to masculine norms in men and higher conformity to female norms in women, the detailed analysis of the relationships between $\mathrm{M} / \mathrm{F}$ and health will clearly show a traditionally masculine pattern for men and a traditionally feminine pattern for women.

Taking into account aforementioned prior findings [16], male nurses' lower conformity to traditional gender roles does not seem to affect their health-related behaviors, which seem to adapt to the traditional masculine health pattern, as reported in national and international surveys and in more specific bibliography[11] [39]-[41]. Similar results are expected for women.

\section{Methods}

\subsection{Participants}

As we proposed to compare the health behavior of male and female nurses and, given the shortage of male nurses, which could skew the characteristics, we took particular care in choosing and matching the group of male and female participants.

The study was carried out with 98 male nurses and 98 female nurses, all of them Spanish, working in one of the tertiary university hospitals of the Community of Madrid, representative of the hospitals of the network of the Spanish National Health System. After an individual meeting in which the goals were explained and confidentiality ensured, out of the 103 male nurses who were on active duty, 98 decided to participate in the study. They were handed a survey and an informed consent form. After analyzing the sociodemographic data shown in Table 1, the female sample was selected; out of the 588 nurses on active duty, 98 were selected who were interested in the study, who worked on the same unit and shift as the male participants, and who presented the highest similarity in the sociodemographic variables to their male counterparts.

The sample of male and female nurses was compared with the data collected from the general Spanish popu- 
lation, exclusively using the variables being a man or a woman and age. Age ranged from 16 to 54 years, and included $99 \%$ of the ages of the nursing population (there was only one female and one male nurse who were beyond this range, aged 56 years).

\subsection{Instruments}

The selected health variables are those most frequently used in research on health, being a man or a woman and $\mathrm{M} / \mathrm{F}$, which were grouped together for practical purposes into four categories: 1) Physical health (self-perceived health, pain, use of medicine and visits to the doctor); 2) Lifestyles (tobacco and alcohol consumption, consumption, sleep problems and physical activity); 3) Mental health as measured by the Spanish adaptation of the GHQ12-General Health Questionnaire-12 [42]; and 4) Work Stress and Job satisfaction (see Table 2).

We used the items from the National Health Survey [43] to measure Physical Health and Lifestyles.

For the reasons expressed above, the instrument chosen to measure conformity to gender norms was the Conformity to Masculine Norms Inventory-CMNI [6] and the Conformity to Feminine Norms Inventory-CFNI [7], adapted for the Spanish population [44] [45]. They have been shown to have satisfactory psychometric properties. All items individual to rate their level of conformity with a series of statements on a 4-point scale ranging from 0 (strongly disagree) to 3 (strongly agree).

The CMNI statements are designed to measure attitudes, beliefs, and behaviors that reflect conformity or nonconformity to 11 subscales associated with masculine gender roles. CMNI is a 94-item measure. The total score ranges from 0 to 282. In Spanish population, this questionnaire obtained a Cronbach's alpha coefficient of 0.89 for the total scale, ranging from 0.67 to 0.81 for the subscales[44].

The CFNI is an 8-factor, 84-item measure of various attitudes, beliefs, and behaviors associated with feminine gender roles, both traditional and non-traditional. The total score ranges from 0 to 252. In Spanish population, Cronbach's alpha coefficient for the total scale was 0.86 , and the values for the subscales ranged between 0.72 and 0.91 [45].

Table 1 includes the description of the CMNI/CNFI scales with a sample of items of each subscale. High scores indicate the participant's conformity to the masculine or feminine roles.

\subsection{Procedure}

A personalized interview was held with each of the hospital male nurses and they were given a detailed report of the research. All those who had volunteered to participate in the study, 98 male nurses, were handed a questionnaire and the relevant consent form. We also guaranteed the anonymity of their data.

Similarly, a personalized interview was held with each of the 588 female nurses from the hospital, and out of these, the same number of participants was selected as for the male sample (98). They also met the same criteria in sociodemographic variables and work contract characteristics as the male nurses. Once selected, the 98 female nurses (randomly selected from among those meeting the requirements) were handed the same questionnaire and relevant consent form, guaranteeing the anonymity of the data. The participants self-completed the questionnaire in approximately 30 minutes.

\section{Results}

No significant differences between male and female nurses were found in the following sociodemographic variables: age, number of months DUE (University Nursing Diploma), number of children, age of first child, age of second child, number of dependents, age of first dependent, age of second dependent, marital status, night shift, and paid help with housework. Males and females only differed significantly in help with housework $\left(\chi^{2}=\right.$ 5.84 , $\mathrm{p}<0.05$ ), in which $41.8 \%$ of women versus $25.5 \%$ of men received this kind of support at home.

Regarding Hypothesis 1 (e.g., With sociodemographic and employment variables being equal and compared to the general population, male nurses will conform less to male norms and female nurses will conform more to female norms), male nurses conformed less to masculine norms and female nurses conformed more to the feminine ones, compared to the general Spanish population. The corresponding data are shown in Table 3 and Table 4.

As shown in Table 3, male nurses scored significantly lower in conformity on 8 of the 11 CMNI scales, and on the total average. Female nurses Table 4, unlike the males, obtained significantly higher scores in conformity to 4 of the 8 CFNI scales, and in the total conformity score. The only scale in which female nurses scored significantly lower than women from the general population was on the scale relating to care: care of children. 
Table 2. Difference of means between female and male nurses in physical health, lifestyles, mental health, stress, and job satisfaction measured with Mann-Whitney’s U statistic.

\begin{tabular}{cccccc}
\hline & Total $^{\mathrm{a}} \mathrm{M}(\mathrm{SD})$ & Female nurses $^{\mathrm{b}} \mathrm{M}(\mathrm{SD})$ & Male nurses $^{\mathrm{c}} \mathrm{M}(\mathrm{SD})$ & $\mathrm{U}$ & $\mathrm{p}$ \\
\hline Self-perceived ill health & $1.93(0.61)$ & $2.04(0.67)$ & $1.83(0.52)$ & 4035 & 0.20 \\
Health complaints & $2.11(1.95)$ & $2.61(2.07)$ & $1.61(1.69)$ & 3357 & 0.000 \\
Number of visits to doctor & $0.48(0.83)$ & $0.54(0.89)$ & $0.42(0.76)$ & 4464 & 0.305 \\
Medicines consumed & $2.67(2.68)$ & $3.15(2.75)$ & $2.19(2.53)$ & 3522 & 0.001 \\
Nr. of cigarettes & $2.84(5.65)$ & $2.98(5.66)$ & $2.69(5.68)$ & 4592 & 0.486 \\
Age at smoking initiation & $17.32(3.95)$ & $16.94(2.06)$ & $17.77(5.4)$ & 467 & 0.446 \\
Frequency of alcohol & $2.60(2.46)$ & $1.98(2.18)$ & $3.21(2.58)$ & 3190 & 0.000 \\
Age at alcohol initiation & $18.56(3.33)$ & $18.61(2.71)$ & $18.52(3.78)$ & 2438 & 0.284 \\
Hours of daily sleep & $7.32(1.02)$ & $7.33(1.02)$ & $7.32(1.02)$ & 4673 & 0.731 \\
Sleep problems & $6.36(2.37)$ & $6.72(2.62)$ & $6(2.05)$ & 4131 & 0.087 \\
Frequency of physical activity & $7.09(9.77)$ & $5.09(9.16)$ & $9.13(9.97)$ & 3121 & 0.000 \\
IMC & $23.99(3.98)$ & $23.02(4.6)$ & $24.96(3.56)$ & 3362 & 0.000
\end{tabular}

${ }^{\mathrm{a}} \mathrm{N}=196 .{ }^{\mathrm{b}} \mathrm{N}=98 .{ }^{\mathrm{c}} \mathrm{N}=98 . \mathrm{U}=$ Mann-Whitney U statistic.

Table 3. Descriptive CMNI and comparison with means of Spanish population.

\begin{tabular}{|c|c|c|c|c|}
\hline CMNI & $\mathrm{Men}^{\mathrm{a}} \mathrm{M}(\mathrm{SD})$ & Spanish male population ${ }^{\mathrm{b}} \mathrm{M}$ (SD) & $\mathrm{t}$ & d \\
\hline 1. Winning & $12.97(3.67)$ & 13.59 (4.08) & $-1.67 \mathrm{~ns}$ & - \\
\hline 2. Emotional control & $14.4(4.51)$ & $14.65(4.47)$ & $-0.55 \mathrm{~ns}$ & - \\
\hline 3. Risk-taking & $13.77(3.56)$ & $14.76(3.61)$ & $-2.77^{* *}$ & -0.27 (low) \\
\hline 4. Violence & $7.74(3.8)$ & $9.96(4.14)$ & $-5.77^{* * *}$ & -0.54 (mod.) \\
\hline 5. Power over women & $6.33(3.02)$ & $8.86(4.59)$ & $-8.3^{* * *}$ & -0.57 (mod.) \\
\hline 6. Dominant & $4.71(1.74)$ & $5.33(2.01)$ & $-3.51^{* *}$ & -0.31 (mod.) \\
\hline 7. Playboy & $13.29(4.58)$ & $14.19(5.46)$ & $-1.95^{*}$ & -0.17 (low) \\
\hline 8. Self-reliance & $4.79(2.62)$ & $6.68(2.60)$ & $-7.15^{* * *}$ & -0.73 (high) \\
\hline 9. Primacy of work & $8.35(2.92)$ & $9.19(3.50)$ & $-2.86^{* *}$ & -0.24 (low) \\
\hline 10. Disdain for homosexuals & $10.26(5.16)$ & $12.27(5.08)$ & $-3.87^{* * *}$ & -0.40 (mod.) \\
\hline 11. Pursuit of status & $9.88(2.28)$ & $9.60(2.64)$ & $1.20 \mathrm{~ns}$ & - \\
\hline Total CMNI & 106.47 (19.54) & 119.13 (22.64) & $-6.41^{* * *}$ & -0.57 (mod.) \\
\hline
\end{tabular}

${ }^{\mathrm{a}} \mathrm{N}=98 .{ }^{\mathrm{b}} \mathrm{N}=727$, from Cuéllar-Flores, Sánchez-López and Dresch [14]; ns $=$ non-significant. ${ }^{*} \mathrm{p}<0.05,{ }^{* *} \mathrm{p}<0.01,{ }^{* * *} \mathrm{p}<0.001$.

With the data obtained, it was observed that the women who work in the second most feminized profession in Spain (after that of teacher) conform more to the traditional feminine role than women from the general Spanish population and vice versa; that is, male nurses conform less to the traditional masculine role than men from the 
general Spanish population.

As far as Hypothesis 2 is concerned (e.g., "Differences between men and women nurses in questions of health emphasize the existence of a differential health pattern for men, unlike the pattern for women”), the health differences between male and female nurses (differences between being a man or a woman) clearly showed the existence of a male pattern for men and a female pattern for women. Table 5 shows the descriptive statistics of the health variables for men and women, as well as the univariate tests for the variable being a man or a woman. The multivariate test indicates that being a man or a woman accounted for a significant proportion of the variance of the dependent variables, (Wilks BEING A MAN OR A WOMAN $(11.183)=0.845, \mathrm{p}=0.001, \eta^{2}=0.155$ ), once the age effect was controlled for (Wilks $\mathrm{AGE}(11.183)=0.882, \mathrm{p}=0.011, \eta^{2}=0.123$.). The univariate tests showed better self-perceived health in men $(\mathrm{p}<0.05)$, fewer medical complaints $(\mathrm{p}<0.001)$, less consumption of medicine ( $\mathrm{p}<0.05$ ), better mental health $(\mathrm{p}<0.05)$, less stress $(\mathrm{p}<0.05)$, higher alcohol consumption $(\mathrm{p}<$ $0.001)$, fewer sleep problems $(\mathrm{p}<0.05)$ and more physical activity $(\mathrm{p}<0.01)$.

Regarding Hypothesis 3 (e.g., "Despite lower conformity to masculine norms in men and higher conformity to female ones in women, the detailed analysis of relationships between $\mathrm{M} / \mathrm{F}$ and health show clearly a traditionally masculine pattern for men and a traditionally feminine pattern for women”), as shown in Table 6 and Table 7, the detailed analysis of relationships between $\mathrm{M} / \mathrm{F}$ and health showed a clearly masculine pattern for

Table 4. Descriptive CFNI and comparison with means of Spanish population.

\begin{tabular}{|c|c|c|c|c|}
\hline CFNI & Women $^{\mathrm{a}} \mathrm{M}$ (SD) & Spanish female population ${ }^{\mathrm{b}} \mathrm{M}$ (SD) & $\mathrm{t}$ & d \\
\hline 1. Relationships & $36.85(4.92)$ & $36.15(6.30)$ & $1.4 \mathrm{~ns}$ & - \\
\hline 2. Thinness & $17.83(6.32)$ & $15.18(5.44)$ & $4.14^{* * *}$ & 0.48 (mod.) \\
\hline 3. Modesty & 13.79 (3.07) & $13.16(3.38)$ & $2.01^{*}$ & 0.19 (low) \\
\hline 4. Domestic & $17.11(2.94)$ & $16.05(4.01)$ & $3.58^{* *}$ & 0.27 (low) \\
\hline 5. Care of children & $20.22(6.88)$ & $21.84(6.57)$ & $-2.33^{*}$ & -0.25 (low) \\
\hline 6. Romantic & $14.12(3.67)$ & $13.72(3.48)$ & $1.08 \mathrm{~ns}$ & - \\
\hline 7. Sexual fidelity & $16.40(4.11)$ & $16.03(5.45)$ & $0.89 \mathrm{~ns}$ & - \\
\hline 8. Appearance & $12.63(3.47)$ & $11.09(3.40)$ & $4.4^{* * *}$ & 0.45 (mod.) \\
\hline Total CFNI & $148.95(15.72)$ & $143.22(20.51)$ & $3.61^{* * *}$ & 0.29 (low) \\
\hline
\end{tabular}

${ }^{\mathrm{a}} \mathrm{N}=98,{ }^{\mathrm{b}} \mathrm{N}=780$, from Sánchez-Lopez, Cuéllar-Flores, Dresch, and Aparicio-Garcia [45]; ns = non-significant, ${ }^{*} \mathrm{p}<0.05,{ }^{* *} \mathrm{p}<0.01,{ }^{* * *} \mathrm{p}<0.001$.

Table 5. Multivariate analysis of covariance: sex controlling for age.

\begin{tabular}{|c|c|c|c|c|}
\hline & Mena M (SD) & Women $^{\mathrm{b}} \mathrm{M}$ (SD) & $F(1,193)$ & $\eta 2$ \\
\hline 1. Self-perceived health & $1.8(0.5)$ & $2.0(0.7)$ & $6.14^{*}$ & 0.03 \\
\hline 2. Health complaints & $1.6(1.7)$ & $2.6(2.1)$ & $14.00^{* * *}$ & 0.06 \\
\hline 3. Medicines consumed & $2.2(2.5)$ & $3.2(2.8)$ & $6.49^{*}$ & 0.03 \\
\hline 4. Visits to the doctor & $0.4(0.8)$ & $0.5(0.9)$ & 1.05 & 0.00 \\
\hline 5. Poor mental health & $1.5(0.6)$ & $2.3(2.8)$ & $4.34^{*}$ & 0.02 \\
\hline 6. Stress & $4.8(1.4)$ & $5.2(1.2)$ & $4.87^{*}$ & 0.02 \\
\hline 7. Work satisfaction & $5.4(1.32)$ & $5.3(1.24)$ & 0.36 & 0.00 \\
\hline 8. Tobacco consumption & $2.7(1.1)$ & $3.0(5.7)$ & 0.11 & 0.00 \\
\hline 9. Alcohol consumption & $3.2(2.6)$ & $2.0(2.2)$ & $13.02^{* * *}$ & 0.06 \\
\hline 10. Sleep problems & $6.0(2.0)$ & $6.7(2.6)$ & $4.59^{*}$ & 0.02 \\
\hline 11. Physical activity & $9.1(10.0)$ & $5.0(9.2)$ & $8.87^{* *}$ & 0.04 \\
\hline
\end{tabular}

${ }^{\mathrm{a}} \mathrm{N}=98 .{ }^{\mathrm{b}} \mathrm{N}=98 .{ }^{*} \mathrm{p}<0.05,{ }^{* *} \mathrm{p}<0.01,{ }^{* * *} \mathrm{p}<0.001 . \eta^{2}=$ ethan statistic. 
men and a clearly feminine pattern for women.

Table 6 presents the partial correlations between the measure of conformity to the 12 gender norms of the CMNI and the health variables, controlling for the age effect. It is particularly significant to be consistent with the traditional role on the CMNI-2 emotional control scale and obtain better scores on self-perceived health $(\mathrm{r}=$ $0.30, \mathrm{p}<0.01)$ and make fewer visits to the doctor $(\mathrm{r}=-0.20, \mathrm{p}<0.05)$. There was a direct relationship between the CMNI-3 Risky Behavior scale and more frequent visits to the doctor $(r=0.25, \mathrm{p}<0.05)$ and the CMNI-4 Violence scale (with an inverse relationship to consumption of medicines) $(r=-0.20, p<0.05)$ and a direct relationship with frequency of alcohol consumption $(r=0.22, p<0.05)$. Male nurses scoring high on the CMNI-6 Dominant scale visited the doctor less frequently $(r=-0.20, \mathrm{p}<0.05)$ and were less satisfied with their job $(\mathrm{r}=$ $-0.24, \mathrm{p}<0.05)$. Male nurses with high scores on the CMNI-7 Playboy scale drank alcohol more frequently $(\mathrm{r}=$

Table 6. Partial correlations between CMNI scales and health variables (controlling for age).

\begin{tabular}{|c|c|c|c|c|c|c|c|c|c|c|c|c|}
\hline & 1 & 2 & 3 & 4 & 5 & 6 & 7 & 8 & 9 & 10 & 11 & $\begin{array}{l}\text { CMNI } \\
\text { Total }\end{array}$ \\
\hline $\begin{array}{l}\text { 1. Self-perceived } \\
\text { ill health }\end{array}$ & -0.05 & $-0.30^{* *}$ & -0.14 & -0.02 & -0.14 & 0.01 & -0.01 & -0.00 & -0.10 & -0.12 & -0.00 & -0.19 \\
\hline $\begin{array}{l}\text { 2. Health } \\
\text { complaints }\end{array}$ & 0.15 & -0.16 & -0.02 & -0.07 & -0.12 & 0.05 & -0.13 & 0.00 & 0.01 & $-0.28^{* *}$ & 0.17 & -0.12 \\
\hline $\begin{array}{l}\text { 3. Medicines } \\
\text { consumed }\end{array}$ & -0.04 & -0.11 & 0.04 & $-0.20^{*}$ & -0.15 & -0.13 & -0.13 & -0.04 & -0.04 & -0.10 & 0.02 & -0.17 \\
\hline $\begin{array}{l}\text { 4. Visits to the } \\
\text { doctor }\end{array}$ & 0.02 & $-0.20^{*}$ & $0.25^{*}$ & -0.14 & -0.09 & $-0.20^{*}$ & -0.08 & -0.14 & -0.08 & -0.17 & 0.09 & -0.14 \\
\hline $\begin{array}{l}\text { 5. Poor mental } \\
\text { health }\end{array}$ & 0.08 & -0.11 & -0.02 & -0.03 & -0.08 & 0.06 & -0.00 & -0.00 & -0.03 & -0.17 & 0.16 & -0.06 \\
\hline 6. Stress & 0.07 & -0.08 & -0.01 & -0.14 & -0.01 & -0.13 & -0.02 & 0.02 & 0.02 & -0.14 & 0.10 & -0.07 \\
\hline $\begin{array}{l}\text { 7. Work } \\
\text { satisfaction }\end{array}$ & -0.09 & -0.13 & 0.01 & -0.16 & -0.06 & $-0.24^{*}$ & -0.17 & -0.03 & -0.11 & 0.01 & $-0.23^{*}$ & -0.19 \\
\hline $\begin{array}{l}\text { 8. Tobacco } \\
\text { consumption }\end{array}$ & -0.03 & 0.04 & 0.00 & 0.04 & 0.01 & 0.09 & 0.08 & 0.09 & 0.15 & 0.00 & -0.02 & 0.07 \\
\hline $\begin{array}{l}\text { 9. Alcohol } \\
\text { consumption }\end{array}$ & 0.19 & -0.09 & 0.18 & $0.22^{*}$ & 0.12 & 0.18 & $0.32^{* *}$ & -0.05 & -0.02 & 0.06 & $0.24^{*}$ & $0.23^{*}$ \\
\hline 10. Sleep problems & 0.10 & 0.07 & 0.03 & -0.21 & -0.08 & -0.01 & 0.11 & -0.02 & 0.10 & -0.01 & 0.11 & 0.03 \\
\hline $\begin{array}{l}\text { 11. Physical } \\
\text { activity }\end{array}$ & 0.01 & -0.11 & -0.05 & 0.07 & -0.03 & -0.04 & -0.12 & -0.05 & -0.12 & 0.19 & -0.06 & -0.04 \\
\hline
\end{tabular}

CMNI Scales: 1 = Winning; 2 = Emotional control; 3 = Risk-taking; 4 = Violence; 5 = Power over women; $6=$ Dominant; $7=$ Playboy; 8 = Self-reliance; 9 = Primacy of work; 10 = Disdain for homosexuals; $11=$ Pursuit of status. $\mathrm{p}<0.05,{ }^{* *} \mathrm{p}<0.01,{ }^{* * *} \mathrm{p}<0.001$.

Table 7. Partial correlations between CFNI scales and health variables (controlling for age).

\begin{tabular}{lcccccccccc}
\hline & 1 & 2 & 3 & 4 & 5 & 6 & 7 & 8 & CMNI Total \\
\hline 1. Self-perceived ill health & -0.15 & 0.11 & $0.29^{* *}$ & -0.03 & -0.17 & -0.14 & -0.09 & 0.11 & -0.06 \\
2. Health complaints & -0.08 & 0.12 & 0.16 & 0.05 & 0.07 & 0.05 & 0.14 & 0.15 & 0.17 \\
3. Medicines consumed & 0.06 & 0.09 & -0.07 & 0.10 & -0.01 & 0.07 & 0.18 & 0.03 & 0.12 \\
4. Visits to the doctor & -0.12 & 0.07 & 0.17 & 0.10 & -0.07 & -0.01 & -0.01 & 0.10 & 0.02 \\
5. Poor mental health & -0.09 & 0.09 & -0.07 & 0.03 & -0.18 & 0.13 & -0.05 & 0.03 & -0.05 \\
6. Stress & -0.12 & 0.10 & 0.11 & -0.03 & -0.07 & 0.10 & -0.11 & 0.17 & 0.02 \\
7. Work satisfaction & 0.14 & -0.19 & 0.01 & 0.09 & 0.08 & -0.09 & 0.04 & -0.08 & -0.00 \\
8. Tobacco consumption & -0.14 & -0.06 & -0.02 & -0.11 & $-0.21^{*}$ & -0.06 & -0.12 & -0.14 & $-0.25^{* *}$ \\
9. Alcohol consumption & -0.02 & $0.20^{*}$ & $-0.23^{*}$ & -0.07 & -0.12 & $0.22^{*}$ & -0.16 & $0.28^{* *}$ & 0.03 \\
10. Sleep problems & -0.17 & $0.25^{*}$ & -0.02 & -0.05 & -0.12 & -0.02 & -0.11 & -0.05 & -0.06 \\
11. Physical activity & -0.03 & -0.06 & -0.18 & -0.03 & -0.15 & 0.04 & -0.00 & 0.07 & -0.11
\end{tabular}

CFNI scales: 1 = Relationships; 2 = Thinness; 3 = Modesty; 4 = Domestic; 5 = Care of children; $6=$ Romantic; $7=$ Sexual fidelity; $8=$ Appearance. ${ }^{*}$ < $0.05,{ }^{* *} \mathrm{p}<0.01, \stackrel{* * *}{\mathrm{p}}<0.001$. 
0.32, $\mathrm{p}<0.01$ ). Conformity to the traditional male role on the CMNI-10 Disdain for Homosexuality scale was inversely related to the number of health complaints $(r=-0.80, p<0.01$ ), and finally, scoring high on the CMNI-11 Pursuit of Status scale correlated with lower Job Satisfaction $(r=-0.23, p<0.10)$ and with higher alcohol consumption $(\mathrm{r}=0.24, \mathrm{p}<0.05)$.

Table 7 presents the partial correlations between the measure of conformity to the nine CFNI gender norms and the health variable, controlling for the age effect. A high score on the traditional feminine role from the CFNI-2 Thinness scale was associated with higher alcohol consumption $(r=0.20, p<0.05)$ and more sleep problems $(r=0.25, \mathrm{p}<0.05)$. A direct relationship was observed between the CFNI-3 Modesty scale and an increase in the frequency of self-perceived ill health $(r=0.29, \mathrm{p}<0.01)$ and an inverse relationship with alcohol consumption ( $\mathrm{r}=-0.23$, $\mathrm{p}<0.01$ ). The CFNI-5 Care for Children scale correlated with lower tobacco consumption ( $\mathrm{r}=-0.21$, $\mathrm{p}<0.05$ ). High scores on the CFNI-6 Romantic Relationships scale had a direct relationship with frequency of alcohol consumption $(r=0.22, p<0.05)$. Finally, the most statistically significant scale was the CFNI-8 Invest in Image or Appearance, such that scoring high on this scale was directly related to frequency of alcohol consumption $(r=0.28, \mathrm{p}<0.05)$.

\section{Discussion}

The object of this study was to discover the relationships between different components of M/F and health in a special group of the Spanish population, male/female nurses. Firstly, with regard to Hypothesis 1, indeed, male and female nurses in our participant groups, with common sociodemographic variables, show a differential conformity to the gender norms prevailing in Spanish society. That is, in general, male nurses are less masculine and female nurses more feminine than men and women in the general population. Nevertheless, in the case of women, this does not appear to be confirmed for the childcare norm. This could be discussed in the light of other findings on women's health within this occupational context. Women point to the existence of greater role conflicts related to the care of small children and their spouses' lack of co-responsibility as the main risk factors for their mental and physical health [35].

In this work, the demographic variables were included to equate the characteristics of the men, a minority in this profession, with those of the women; that is, to ensure that the gender comparisons were correctly performed. In effect, no significant gender differences were found in these variables, except for two: number of months worked (the women had worked more hours) and help with housework (the women received more help at home). Although neither of these two differences are significant for this work, nor are they a part of our research goals or our hypotheses, it could be interesting to offer a possible interpretation of these differences, on the basis of the authors' knowledge of the female and male nurses who participated in this study. In the first case, the men had probably worked less than the women because of the later age at which they habitually finished their studies, and because of their later incorporation, on average, to this post. With regard to the second difference, we note that the percentage of single people is the same in men and women, as are the rest of the civil statuses. A possible explanation of the fact that the women may receive more help with the housework is that, in the case of male nurses living with a partner, their partner may take care of these tasks, whereas in the case of female nurses living with a partner, their partner may also work outside of the home, so they might pay someone else to do the housework. This interpretation coincides with the results of the studies on the distribution of time carried out in Spain [46].

With regard to the second hypothesis, concerning health differences between men and women, male nurses show better health than female nurses. Female nurses report worse self-perceived health, worse mental health, more health complaints, higher consumption of medicine, more stress and sleep problems, lower alcohol consumption and they perform less physical activity than male nurses. According to the interpretation of some authors, the existence of greater stress in female nurses is the result of more emotional reaction to their professional workload (as a paid professional) and their reproductive, or domestic, workload [47] and to their lower valuation both inside and outside the home, low acknowledgement by male nurses, doctors, and superiors, or lack of time to balance their work and family life [36] [48]. Furthermore, this differential illness pattern for male and female nurses is similar to that found in women and men in general: women have worse physical health and higher illness rates [15] [49], and men are more prone to alcohol and tobacco consumption.

Therefore, the data of this study confirm that male and female nurses follow the same general tendency that, since the 1970s, has been known as the "sex morbidity-mortality paradox" [50]. In either case, according to Macintyre, Ford, and Hunt (1999), "it is important to continue to search for empirical evidence of gender differenc- 
es (or lack of them) in illness reporting” (p. 97), in order to continue to provide primary data to studies like those of Kulminski et al. [50], who found, on the one hand, changes across ages and time in the traditional morbidity-mortality paradox, and, on the other, the existence of an inverse morbidity paradox (males have worse health, but less life risk).

As for Hypothesis 3, the analysis of the inter-gender relationships (conformity to gender norms) and health highlights a clearly masculine pattern for men and a clearly feminine one for women. Data indicate higher alcohol consumption and greater conformity to masculine norms in male nurses, and lower tobacco consumption and higher conformity to female norms in female nurses. As in previous works [6] [14], the relationships discovered between $\mathrm{M} / \mathrm{F}$ and health are very moderate, but they confirm the traditionally male and female health habits. Moreover, as in these previous works, the total measure of conformity to gender norms shows little relationship with health indices. This confirms the suitability of multidimensional scales, like those used in this work (CFNI/CMNI) geared to ascertaining the dimensions of conformity to gender norms that have a greater relationship with health indexes.

A detailed analysis of the scores in each of the scales reveals a pattern of illness in male nurses which is still masculine despite their lower conformity, as a group, to masculine norms, and a clearly feminine illness pattern in female nurses. In fact, in the case of male nurses, conformity to the emotional control norm is related to better self-perceived health and fewer visits to the doctor; conformity to violence is related to lower use of medicines and higher use of alcohol. Dominance is associated with fewer visits to the doctor and lower job satisfaction: womanizing is related to higher alcohol consumption, and contempt for homosexuality, with fewer health complaints. Finally, pursuit of status is associated with lower job satisfaction and higher alcohol consumption. The relationships between alcohol consumption and traditionally masculine behaviors such as self-control, a playboy attitude, or promiscuity, and violence have already been confirmed in previous studies [6] [9] [14] [51].

However, in the male participants of this study, we observed a lower score in the traditional masculine role, coinciding with the consulted bibliography [31] [52] [53]. This lower conformity to the traditional masculine role can have positive effects on these men's health, as numerous studies have found that traditionally masculine men consume more alcohol and other drugs, drive more recklessly, take more sexual risks, undergo fewer health checkups, etc. A positive relation was observed between high scores on the Risk-taking scale and an increase of visits to the doctor, which may be explained by this increase of risk behaviors. Also, the relationships between higher assessment of one's social position and lower job satisfaction may be due to the type of work undertaken by these male hospital nurses, in which they find few opportunities to increase their social prestige. This may also give rise to higher alcohol consumption.

In the case of the women, greater conformity to the Care of Children norm is related to lower tobacco consumption, whereas higher scores on the Modesty scale are related to worse self-perceived health and lower alcohol consumption. These characteristics are compatible with a traditional gender pattern, in which the tobacco habit and alcohol consumption are not related to feminine habits. Traditional femininity emerges as a protector from consumption of tobacco, as reported by Sánchez-López et al. [14].

Similarly, relationships between the importance given to being thin and sleep problems is congruent with the feminine health pattern, in which women display more sleep problems than males, such that the more they conform to traditional female gender norms, the more sleep problems they have. The association of femininity with poor health in female nurses found in other studies [34] [36] is therefore confirmed herein for some of the social norms such as Thinness, Modesty, Appearance and Romantic Relationships.

However, relationships between alcohol consumption and conformity to some female gender norms identifies a risk pattern for health related to the greater importance of thinness, romantic relationships and image in this group of women.

In general, these results reveal the existence of relationships between $\mathrm{M} / \mathrm{F}$ and health in the nursing profession, similar to those identified in other social and occupational contexts [6] [10] [15] [54]. However, the consideration of gender from a broader multidimensional perspective, such as used in this work, has enabled us to study in depth some of these relationships, identify differential health behaviors for male and female nurses, and highlight specific relationship mechanisms between $\mathrm{M} / \mathrm{F}$ and health for men and women in atypical occupational contexts. This has already been reported in some qualitative studies [55] describing how a gender imbalance may give rise to much pressure and restraint in the minority group, due to greater visibility and status symbolism.

In the case of nursing, for women, these mechanisms are related to the practice of a traditionally female activ- 
ity, but in a professional context where they are no longer the center of attention. Our results confirm higher femininity in these women, also found in female nurses of other nationalities [31] [34]. The results could also identify specific roles that involve greater health risk, such as conformity to norms of thinness, modesty, appearance and romantic relationships.

In the case of the men, it is related to practicing a traditionally feminine role in an occupational context predominated by women. Here, being a minority would give rise to pressure to develop role norms related to male gender role stereotypes and fear of becoming feminized or stigmatized [56]. Nonetheless, it also appears to endow them with greater insight and a greater possibility of promotion than their female counterparts [55]. This advantage could also partially explain the better health found in male nurses, both in comparison with women and compared to men in general, as reported in other studies [16], and it confirms some of men's classic advantages in professional feminized environments [26] [28]. These results even provide evidence of a predominant masculinity that exerts its influence on this professional setting, maintaining a specific pattern, thereby ensuring this internal (generation of social inequality among men) and external (institutionalization of men's dominance of women) predominance of masculinity [29].

\section{Limitations and Future Perspectives}

This study has some limitations. One of them is the use of self-reported measures to evaluate diseases, which leads to potential misclassification of these outcomes and to special acceptability bias. Future studies should include objective measures of diseases, in addition to subjective measures, to verify whether the subjective and objective measures correlate (e.g., laboratory tests confirming the diagnosis of diseases, immunological system indicators, and other biomarkers).

Another limitation is the generalizability of results like these to other populations. In order to generalize these results, it is important to bear in mind that the scales used in this study to measure $\mathrm{M} / \mathrm{F}$ have proved their worth in different countries /cultures (in Asian-American, Italian-American, and Anglo-American people in the USA, and in Spanish, Australian and Nigerian populations) [9] [57]-[59].

Another limitation is that we did not measure masculinity in the women or femininity in the men. At least since the publication of the BSRI [3] and of the Personal Attributes Questionnaire [4], the idea that masculinity and femininity are multidimensional constructs is broadly accepted [60]. However, the operationalization of this idea with sufficient psychometric guarantees faces two difficulties. The first is that measures of masculinity and/or femininity are typically developed using single-gender samples [61]. The second one is that only a few studies have examined M/F norm conformity among samples of women/men [60]. The instrument used in this work, the CMNI/CFMI, carefully selected for the above-mentioned reasons, is no exception. Only recently [61], and after the initiation of the study presented herein, the psychometric proprieties of the CMNI-46 (a brief version of the CMNI) been shown to be adequate among women, which, according to the authors, would allow researchers to feel confident "that the measure is valid for use with samples of women" (p. 328) [61]. We know of no work that has validated the CFNI in men.

Therefore, although the authors of this work are convinced of the added utility of measuring masculinity in women and femininity in men, till now, this was impossible (without ignoring the basic methodological requirements). However, this does not invalidate the utility of the data presented herein, as we have attempted to make clear in the preceding pages. The availability of psychometrically adequate instruments for cross-application will contribute more knowledge of gender patterns, for example, and allow us to deepen our conception of masculinity and femininity such as the degree of people's conformity (emotional, cognitive and/or behavioral) to a series of gender norms that designate what is considered socially appropriate for women and men, transmitted by each culture, in a specific historical moment, so they can be identified by the members of each society, as we have maintained in this work, following [6] [7].

\section{Acknowledgements}

Research funded by the Women's Institute (Ministerio de Salud, Politica Social e Igualdad), reference number 18/09. We thank the Hospital Universitario de Getafe (Spain) for its involvement in the project.

\section{References}

[1] World Health Organization (2007) What Is a Gender-Based Approach to Public Health? 
http://www.who.int/features/qa/56/en/index.html

[2] Yoder, J.D. and Kahn, A.S. (2003) Making Gender Comparisons More Meaningful: A Call for More Attention to Social Context. Psychology of Women Quarterly, 27, 281-290.

[3] Bem, S. (1974) The Measurement of Psychological Androgyny. Journal of Consulting and Clinical Psychology, 42, 155162. http://dx.doi.org/10.1037/h0036215

[4] Helmreich, R.L, Spence, J.T. and Wilhelm, J.A. (1981) A Psychometric Analysis of the Personal Attributes Questionnaire. Sex Roles, 7, 1097-1108. http://dx.doi.org/10.1007/bf00287587

[5] Auster, C.J. and Ohm, S.C. (2000) Masculinity and Femininity in Contemporary American Society: A Reevaluation Using the Bem Sex-Role Inventory. Sex Roles, 43, 499-528. http://dx.doi.org/10.1023/a:1007119516728

[6] Mahalik, J.R., Locke, B., Ludlow, L., Diemer, M., Scott, R.P.J. and Gottfried, M. (2003) Development of the Conformity to Masculine Norms Inventory. Psychology of Men and Masculinity, 4, 3-25. http://dx.doi.org/10.1037/1524-9220.4.1.3

[7] Mahalik, J.R., Morray, E.B., Coonerty-Femiano, A., Ludlow, L.H., Slattery, S.M. and Smiler, A. (2005) Development of the Conformity to Feminine Norms Inventory. Sex Roles, 52, 417-435. http://dx.doi.org/10.1007/s11199-005-3709-7

[8] Mahalik, J.R. (2000) Men’s Gender Role Conflict as Predictors of Self-Ratings on the Interpersonal Circle. Journal of Social and Clinical Psychology, 19, 276-292. http://dx.doi.org/10.1521/jscp.2000.19.2.276

[9] Liu, W.M. and Iwamoto, D.K. (2007) Conformity to Masculine Norms, Asian Values, Coping Strategies, Peer Group Influences and Substance Use among Asian American Men. Psychology of Men and Masculinity, 8, 25-39. http://dx.doi.org/10.1037/1524-9220.8.1.25

[10] Mahalik, J.R., Burns, S.M. and Syzdek, M. (2007) Masculinity and Perceived Normative Health Behaviors as Predictors of Men's Health Behaviors. Social Science \& Medicine, 64, 2201-2209. http://dx.doi.org/10.1016/j.socscimed.2007.02.035

[11] Sánchez-López, M.P., López-García, J.J., Dresch, V. and Corbalán, J. (2008) Sociodemographic, Psychological and Health-Related Factors Associated with Poor Mental Health in Spanish Women and Men in Midlife. Women \& Health, 48, 445-465. http://dx.doi.org/10.1080/03630240802575096

[12] Addis, M. and Mahalik, J. (2003) Men, Masculinity, and the Contexts of Help Seeking. American Psychologist, 58, 514. http://dx.doi.org/10.1037/0003-066X.58.1.5

[13] Prakash, J., Kotwal, A.S.M., Ryali, V.S.S.R., Srivastava, K., Bhat, P.S. and Shashikumar, R. (2010) Does Androgyny have Psychoprotective Attributes? A Cross-Sectional Community-Based Study. Industrial Psychiatry Journal, 19, 119124. http://dx.doi.org/10.4103/0972-6748.90343

[14] Sánchez-López, M.P., Cuéllar-Flores, I. and Dresch, V. (2012) The Impact of Gender Roles on Health. Women \& Health, 52, 182-196. http://dx.doi.org/10.1080/03630242.2011.652352

[15] Kirchengast, S. and Haslinger, B. (2008) Gender Differences in Health-Related Quality of Life among Healthy Aged and Old-Aged Austrians: Cross-Sectional Analysis. Gender Medicine, 5, 270-278. http://dx.doi.org/10.1016/j.genm.2008.07.001

[16] Limiñana-Gras, R.M., Sánchez-López, M.P., Saavedra-San Román, A.I. and Corbalán-Berná, J. (2013) Health and Gender in Female Dominated Occupations: The Case of Male Nurses. The Journal of Men's Studies, 21, 135-148. http://dx.doi.org/10.3149/jms.2102.135

[17] World Health Organization (2002) Gender and Women’s Mental Health. Retrieved on 5 January, from: Mental Health. http://www.who.int/mental_health/prevention/genderwomen/en/

[18] Sánchez-López, M.P., Rivas-Díez, R. and Cuéllar-Flores, I. (2013) Masculinity and Femininity as Predictors of Tobacco and Alcohol Consumption in Spanish University Students. Health and Addictions, 13, 15-22.

[19] Brabete, A.C. and Sánchez-López, M.P. (2012) How Does the Gender Influence People’s Health? Data of a Sample of Romanian People Living in Spain. Procedia-Social and Behavioral Sciences, 33, 148-152. http://dx.doi.org/10.1016/j.sbspro.2012.01.101

[20] World Health Organization (2003) Gender, Health and Ageing. WHO, Geneva.

[21] Deeks, A., Lombard, C., Michelmore, J. and Teede, H. (2009) The Effects of Gender and Age on Health-Related Behaviors. BMC Public Health, 9, 213-221. http://dx.doi.org/10.1186/1471-2458-9-213

[22] Instituto Nacional de Estadística (INE) (2012) Estadística de Profesionales Sanitarios Colegiados, año 2012 [Survey of the Number of Health Professionals Registered in Spain, 2012]. INE, Madrid. http://www.ine.es/jaxi/menu.do?L= 0\&type= pcaxis\&path=/t15/p416\&file= inebase

[23] Mullan, B. and Harrison, J. (2008) Male and Female Nursing Applicants' Attitudes and Expectations towards Their Future Careers in Nursing. Journal of Research in Nursing, 13, 527-539. http://dx.doi.org/10.1177/1744987107085500 
[24] The National Union of Nurses Associations, Republic of China (2008) Statistics of Nurses in Taiwan. http://www.nurse.org.tw/DataSearch/Manpower.aspx/

[25] Battice, J. (2010) The Changing Face of Nursing in a Developing Country. Journal of Clinical Nursing, 19, $1765-1766$. http://dx.doi.org/10.1111/j.1365-2702.2009.02882.x

[26] Kanter, R.M. (1977) Men and Women of the Corporation. Basic Books, New York.

[27] Kmec, J.A. (2008) The Process of Sex Segregation in a Gender-Typed Field: The Case of Male Nurses. Sociological Perspectives, 51, 259-279. http://dx.doi.org/10.1525/sop.2008.51.2.259

[28] Williams, C.L. (1995) Still a Man’s World. Men Who Do Women’s Work. University of California Press, Berkeley.

[29] Connell, R.W. and Messerschmidt, J.W. (2005) Hegemonic Masculinity: Rethinking the Concept. Gender \& Society, 19, 829-859. http://dx.doi.org/10.1177/0891243205278639

[30] Loughrey, M. (2008) Just How Male Are Male Nurses? Journal of Clinical Nursing, 17, 1327-1334. http://dx.doi.org/10.1111/j.1365-2702.2007.02250.x

[31] Fisher, M.J. (2011) Sex Differences in Gender Characteristics of Australian Nurses and Male Engineers: A Comparative Cross-Sectional Survey. Contemporary Nurse: A Journal for the Australian Nursing Profession, 39, 36-50. http://dx.doi.org/10.5172/conu.2011.39.1.36

[32] Canadian Institute for Health Information. (2007) The Work and Health of Nurses. How Do Nurses’ Perceptions Vary across Canada? CIHI, Ottawa.

[33] Tucker, S.J., Harris, M.R., Pipe, T.B. and Stevens, S.R. (2010) Nurses’ Ratings of Their Health and Professional Work Environments. American Association of Occupational Health Nurses, 58, 253-267.

[34] Ushiro, R. and Nakayama, K. (2010) Gender Role Attitudes of Hospital Nurses in Japan: Their Relation to Burnout, Perceptions of Physician-Nurse Collaboration, Evaluation of Care, and Intent to Continue Working. Japan Journal of Nursing Science, 7, 55-64. http://dx.doi.org/10.1111/j.1742-7924.2010.00138.x

[35] Talley, G., Thomas, R.E. and Brown, K.C. (2009) A Health Comparison of Alabama Nurses versus US, UK and Canadian Normative Populations. Journal of Orthopedic Nursing, 13, 172-182. http://dx.doi.org/10.1016/j.joon.2009.03.005

[36] Evans, O. and Steptoe, A. (2002) The Contribution of Gender-Role Orientation, Work Factors and Home Stressors to Psychological Wellbeing and Sickness Absence in Male-and Female-Dominated Occupational Groups. Social Science \& Medicine, 54, 481-492. http://dx.doi.org/10.1016/S0277-9536(01)00044-2

[37] Steinfeldt, J.A., Zakrajzek, R., Carter, H. and Steinfeldt, M.C. (2011) Conformity to Gender Norms among Female Student-Athletes: Implications for Body Image. Psychology of Men and Masculinity, 12, 401-416. http://dx.doi.org/10.1037/a0023634

[38] Izú, M., Cortez, E.A., Valente, G.C. and Silvino, Z.R. (2011) Trabalho noturno como factor de risco na carcinogênese [Working Nights as a Risk and Carcinogenic Factor]. Ciencia y Enfermeria, 17, 83-95. http://dx.doi.org/10.4067/S0717-95532011000300008

[39] European Union (2011) The State of Men’s Health in Europe. European Union, Brussels.

[40] Ministerio de Sanidad y Consumo [Ministry of Health and Consumption] (2005) Informe Salud y Género (Report on Health and Gender]. Ministerio de Sanidad y Consumo, Madrid.

[41] Ministerio de Sanidad, Servicios Sociales e Igualdad [Ministry of Health, Social Services, and Equality] (2006) Encuesta nacional de salud [National Health Survey]. Instituto de Información Sanitaria e Instituto Nacional de Estadística, Madrid. http://www.msps.es/estadEstudios/estadisticas/encuestaNacional/encuestaNac2006/encuestaNacionalSalud2006.pdf

[42] Sanchez-Lopez, M.P. and Dresch, V. (2008) The 12-Item General Health Questionnaire (GHQ-12): Reliability, External Validity and Factor Structure in the Spanish Population. Psicothema, 20, 839-843.

[43] Ministerio de Sanidad, Política Social e Igualdad [Ministry of Health, Social Policy, and Equality] (2013). Encuesta nacional de salud [National Health Survey]. Instituto Nacional de Estadística, Madrid.

[44] Cuellar-Flores, I., Sánchez-López, M.P. and Dresch, V. (2011) El Inventario de Conformidad con las Normas de Género Masculinas (CMNI) en la población española [Conformity to Masculine Gender Norms Inventory in the Spanish Population]. Anales de Psicología, 27, 170-178.

[45] Sánchez-López, M.P., Cuellar-Flores, I., Dresch, V. and Aparicio-Garcia, M. (2009) Conformity to Feminine Gender Norms in the Spanish Population. Social Behavior and Personality, 37, 1171-1185. http://dx.doi.org/10.2224/sbp.2009.37.9.1171

[46] Instituto de la Mujer [Women’s Institute] (2013) Estadísticas. Usos del tiempo I [Statistics. Uses at time I]. Retrieved on 5 January 2014, from: Mental. http://www.inmujer.es/estadisticas/consulta.do?area= 6

[47] Hsu, C.H.I., Chen, S.H., Yu, H.Y. and Lou, J.H. (2010) Job Stress, Achievement Motivation and Occupational Burnout 
among Male Nurses. Journal of Advanced Nursing, 66, 1592-1601. http://dx.doi.org/10.1111/j.1365-2648.2010.05323.x

[48] Rotenberg, L., Fernandez-Portela, L., Banks, B., Griep, R.H., Fischer, F.M. and Landsbergis, P. (2008) A Gender Approach to Work Ability and Its Relationship to Professional and Domestic Work Hours among Nursing Personnel. Applied Ergonomics, 39, 646-652. http://dx.doi.org/10.1016/j.apergo.2008.02.013

[49] Cuellar-Flores, I., Limiñana-Gras, R.M. and Sánchez-López, M.P. (2013) The Health of Paid Caregivers: A CrossSectional Study in Spanish Population. Psychology, 4, 50-56. http://dx.doi.org/10.4236/psych.2013.46A1008

[50] Kulminski, A.M., Culminskaya, I.V., Ukraintseva, S.V., Arbeev, K.G., Land, K.C. and Yashin, A.I. (2008) Sex-Specific Health Deterioration and Mortality: The Morbidity-Mortality Paradox over Age and Time. Experimental Gerontology, 43, 1052-1057. http://dx.doi.org/10.1016/j.exger.2008.09.007

[51] Mahalik, J.R., Lagan, H.D. and Morrison, J.A. (2006) Health Behaviors and Masculinity in Kenyan and U.S. Male College Students. Psychology of Men and Masculinity, 7, 191-202. http://dx.doi.org/10.1037/1524-9220.7.4.191

[52] Muldoon, O. and Reilly, J. (2003) Career Choice in Nursing Students: Gendered Constructs as Psychological Barriers. Journal of Advanced Nursing, 43, 93-100. http://dx.doi.org/10.1046/j.1365-2648.2003.02676.x

[53] Pontin, D. (1988) The Use of Profile Similarity Indices and the Bem Sex Role Inventory in Determining the Sex Role Characterization of a Group of Male and Female Nurses. Journal of Advanced Nursing, 13, 768-774. http://dx.doi.org/10.1111/j.1365-2648.1988.tb00568.x

[54] Bird, C.E. and Rieker, P.P. (2008) Gender and Health. The Effects of Constrained Choices and Social Policies. Cambridge University Press, New York. http://dx.doi.org/10.1017/CBO9780511807305

[55] Simpson, R. (2009) Men in Caring Occupations: Doing Gender Differently. Palgrave Macmillan, New York. http://dx.doi.org/10.1057/9780230594333

[56] Lupton, B. (2000) Maintaining Masculinity: Men Who Do Women’s Work. British Journal of Management, 11, 33-48. http://dx.doi.org/10.1111/1467-8551.11.s1.4

[57] Locke, B.D. and Mahalik, J.R. (2005) Examining Masculinity Norms, Problem Drinking, and Athletic Involvement as Predictors of Sexual Aggression. Journal of Counseling Psychology, 52, 279-283. http://dx.doi.org/10.1037/0022-0167.52.3.279

[58] Mahalik, J.R., Levi-Minzi, M. and Walker, G. (2007) Masculinity and Health Behaviors in Australian Men. Psychology of Men \& Masculinity, 8, 240-249. http://dx.doi.org/10.1037/1524-9220.8.4.240

[59] Tager, D. and Good, G.E. (2005) Italian and American Masculinities: A Comparison of Masculine Gender Role Norms. Psychology of Men \& Masculinity, 6, 264-274. http://dx.doi.org/10.1037/1524-9220.6.4.264

[60] Smiler, A.P. (2006) Conforming to Masculine Norms: Evidence for Validity among Adult Men and Women. Sex Roles, 54, 767-775. http://dx.doi.org/10.1007/s11199-006-9045-8

[61] Parent, M.C. and Smiler, A.P. (2013) Metric Invariance of the Conformity to Masculine Norms Inventory-46 among Women and Men. Psychology of Men \& Masculinity, 14, 324-328. http://dx.doi.org/10.1037/a0027642 
Scientific Research Publishing (SCIRP) is one of the largest Open Access journal publishers. It is currently publishing more than 200 open access, online, peer-reviewed journals covering a wide range of academic disciplines. SCIRP serves the worldwide academic communities and contributes to the progress and application of science with its publication.

Other selected journals from SCIRP are listed as below. Submit your manuscript to us via either submit@scirp.org or Online Submission Portal.
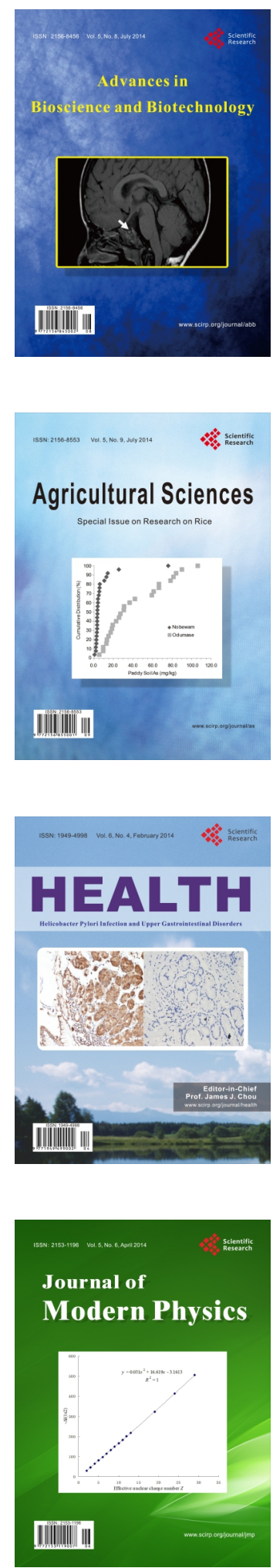
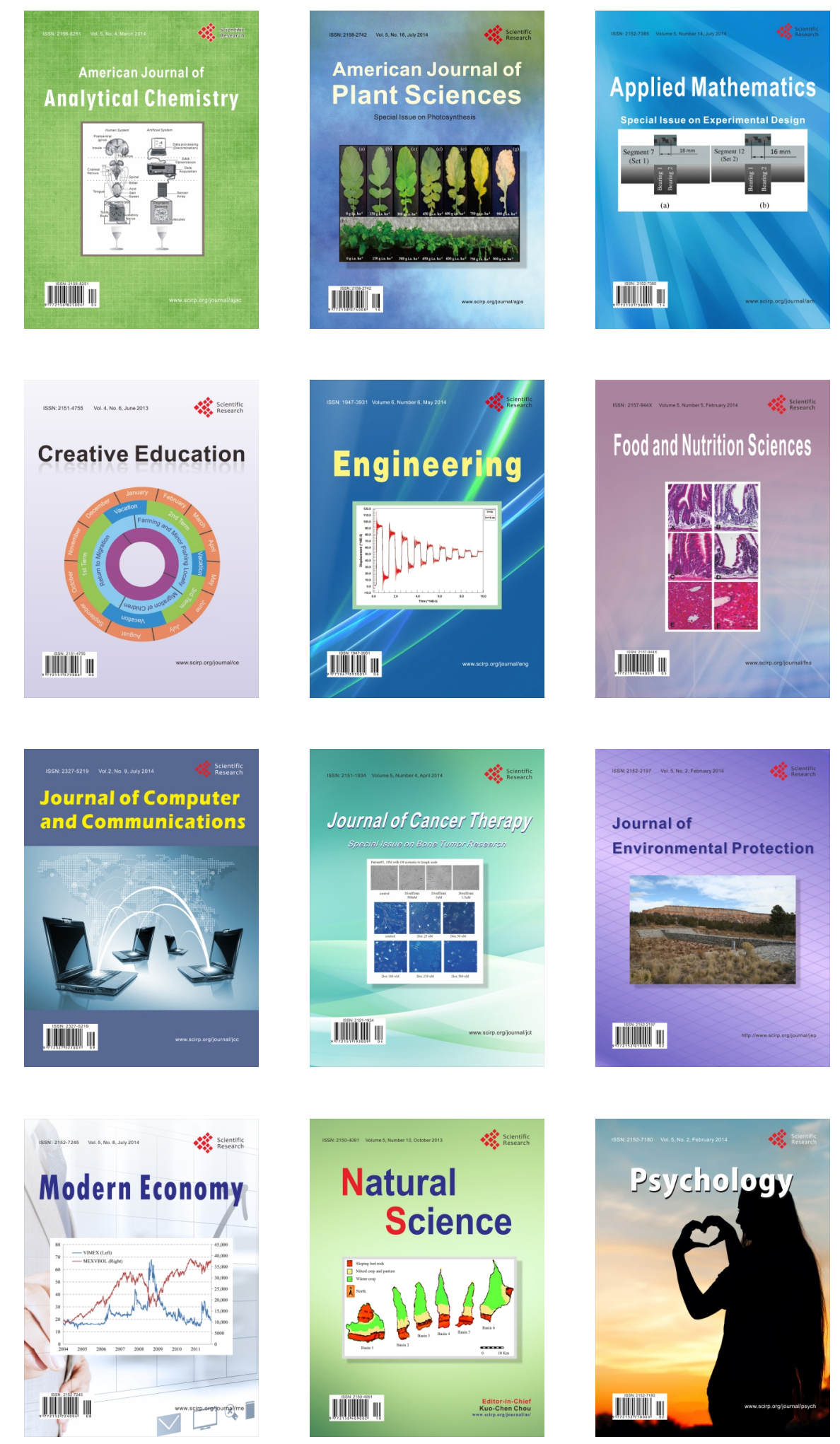